\title{
BMJ Open Twenty-five years after the introduction of Evidence-based Medicine: knowledge, use, attitudes and barriers among physiotherapists in Italy - a cross-sectional study
}

To cite: Castellini G, Corbetta D, Cecchetto S, et al. Twenty-five years after the introduction of Evidence-based Medicine: knowledge, use, attitudes and barriers among physiotherapists in Italy - a cross-sectional study. BMJ Open 2020;10:e037133. doi:10.1136/ bmjopen-2020-037133

- Prepublication history and additional material for this paper are available online. To view these files, please visit the journal online (http://dx.doi org $/ 10.1136 /$ bmjopen-2020037133).

Received 27 January 2020 Revised 16 April 2020 Accepted 29 April 2020

\section{Check for updates}

(C) Author(s) (or their employer(s)) 2020. Re-use permitted under CC BY-NC. No commercial re-use. See rights and permissions. Published by BMJ.

For numbered affiliations see end of article.

Correspondence to Dr Greta Castellini; greta.castellini@ grupposandonato.it

\section{ABSTRACT}

Objectives To explore the knowledge, use, attitudes towards Evidence-based Medicine, also known as Evidence-based Practice (EBP), and perceived barriers to its dissemination among physiotherapists.

Design Cross-sectional study.

Setting and participants Members of the Italian Association of Physiotherapists $(n=2000)$ were invited to participate in an online survey about EBP knowledge and use.

Primary outcome measures The survey questionnaire comprised four sections: (1) respondent characteristics; (2) knowledge of EBP principles; (3) attitude, use and perceived effectiveness of EBP; (4) perceived barriers to implementing EBP in clinical practice.

Results Out of 2000 physiotherapists, 1289 participated in the survey (64.5\% response rate). Overall, $90 \%$ perceived EBP as useful and necessary for their clinical practice. More than $85 \%$ stated that they were familiar with the principles of EBP, $75 \%$ reported that they were able to search online databases for relevant information and $60 \%$ reported that they were able to understand statistical analyses. However, $56 \%$ believed that patient preferences and $39 \%$ that clinical expertise are not part of the EBP model. Half stated that they understood and could explain the term 'meta-analysis' but only $17 \%$ knew what a forest plot is and just $20 \%$ correctly judged the finding of a given meta-analysis. Lack of time was reported as the main barrier to EBP.

Conclusion The majority of Italian physiotherapists overrated their knowledge about EBP, demonstrating a gap between perceived and actual knowledge of EBP in this population.

\section{INTRODUCTION}

Evidence-based Medicine, also known as Evidence-based Practice (EBP), is an internationally recognised movement defined as 'the conscientious, explicit, and judicious use of current best evidence in making decisions about the care of individual patients. The practice of Evidence-based Medicine means
Strengths and limitations of this study

- A national web-based survey within a crosssectional study of Italian physiotherapists was performed.

- The survey response rate was $64.5 \%$ (highmoderate) in this sample of 2000 physiotherapists.

- Self-reported data and potential non-response bias may affect the results and interpretation of this cross-sectional study.

- Generalisability is limited to a selected population.

integrating individual clinical expertise with the best available external clinical evidence from systematic research.' ${ }^{, 1}$ The identification and application of patient preferences should be part of decision making. ${ }^{2}$ This concept of shared decision making has gained attention in the last decade, with physical medicine and rehabilitation clinicians being more likely to involve patients in making informed decisions. ${ }^{13}$

Using the best available evidence to make healthcare decisions optimises health outcomes. Issues in EBP have attracted growing debate and discussion, ${ }^{245}$ as seen in the increase in the number of scientific articles directly relevant to physiotherapy practice $^{67}$ : between 1995 and 2015, randomised controlled trials (RCTs) and systematic reviews (SRs) rose from $45.1 \%$ to $59.4 \%$, and from $0 \%$ to $14.6 \%$, respectively. ${ }^{8}$ Taken together, RCTs and SRs accounted for $74 \%$ of physiotherapy research publications in 2015 compared with $45 \%$ two decades earlier. ${ }^{8}$

Keeping up with this abundance of research poses a challenge for most clinicians. Not surprisingly, the transfer of research findings into practice is often described as slow, haphazard and unpredictable. ${ }^{9} \quad$ Several 
studies have explored the perceived knowledge, use, attitudes and barriers to EBM among physiotherapists, ${ }^{10-18}$ however, no similar research exists in the relatively recent Italian context: 3-year, full-time university degree courses in physiotherapy were established in 2006. The courses are a mix of academic studies and mandatory internship starting from the first year. Completion of the bachelor's degree is prerequisite to admission to the 'Laurea Magistrale' (equivalent to the European Master of Science) and a Doctoral Programme.

In addition, no studies to date have investigated the strength of the link between perceived and actual knowledge or highlighted the possible gap that may explain the difficulty physiotherapists have in applying the principles of EBM in clinical practice.

With these points in mind, we investigated the knowledge, the use of and the attitude towards EBP among Italian physiotherapists and the barriers they perceived to adopting its implementation. Secondary aims were to investigate the gap between perceived and actual knowledge of EBP principles among physiotherapists and to analyse the association between their perceived and actual knowledge and demographic characteristics.

\section{METHODS}

\section{Design}

For this cross-sectional study, we conducted an online closed survey of members of the Italian Association of Physiotherapists (Associazione Italiana Fisioterapisti (AIFI) ). We developed a survey questionnaire and posted it on a SurveyMonkey platform ${ }^{19}$ for data collection. The survey was e-mailed directly to AIFI members and made available for a period of 6 weeks from May to June 2018. The study followed the Guidelines for Reporting SurveyBased Research. ${ }^{20} 21$

\section{Patient and public involvement}

Although there was no direct involvement of patients or the public, the AIFI assisted in the design and delivery of the study. They also sent the questionnaire directly to participants.

\section{Study sample}

Before the survey questionnaire was posted online, the AIFI sent an invitation in their e-mail newsletter to all AIFI members explaining the aim and content of the survey. The invitation explained the purpose of the survey, the time needed to complete it (10 minutes) and the type of questions that participants could expect to find. The time estimation was a median based on a questionnaire piloted with six expert physiotherapists in EBP. The survey was linked to a unique respondent that did not display the survey a second time once completed. The survey questionnaire was posted on 4 May 2018. Two weeks later, the AIFI sent out an e-mail reminder to AIFI members who had not yet responded. Responses were treated anonymously.
The AIFI membership database contains more than 10000 addresses of physiotherapist members (12514 as of the end of 2019) out of an estimate of 65000 physiotherapists. Only 2000 are considered active members, which the AIFI secretariat defines as members who received emails, exchange and share links on the AIFI website and app, read the AIFI newsletter and interact with the AIFI channels.

\section{Sample size calculation}

We used the sample size calculator ${ }^{2223}$ provided by SurveyMonkey. The sample size is the number of completed responses we expected to receive: based on a population size of 10000 (the total number of people we intended to invite to participate in the study, ie, total number of AIFI members registered at the time of the survey), a $5 \%$ margin of error (how accurately the survey results reflect the views of the overall population) and a sampling confidence level of $95 \%$ (how confident we can be that the population would select an answer within a certain range). The calculated sample size of completed responses was 370 completed answers. We expected that sending the survey to a target sample of 2000 active members would guarantee 370 completed responses.

\section{Survey questionnaire}

The questionnaire was developed based on similar questionnaires reported in the literature. ${ }^{12} 1524$ Since the aim was to investigate several contents (perceived and real knowledge, use, attitude and barriers), we adapted the existing instruments to create an ad hoc survey that would reflect the above contents. Before sending out the survey, we piloted the questionnaire with six expert physiotherapists in EBP (four senior and two junior researchers, with an average of 8 and 3 years of EBP expertise, respectively) to assess its clarity and accuracy. After revision, the final questionnaire version consisted of 26 items divided into four sections: (1) respondent characteristics (items $1-8)$; (2) knowledge and ability to critically appraise the literature (items 9-16); (3) use and perceived effectiveness of EBP (items 17-24); (4) perceived barriers to the implementation of EBP in clinical practice (items 25 and 26). Response to all items was mandatory. The questionnaire was written in Italian to make it more suitable for this sample (online supplementary file 1-questionnaire, English version).

Section 1 covered demographic characteristics; section 2 , item 9 , asked respondents to indicate the origin of their knowledge about EBP basics. If they stated that they did not know the EBP model, the questionnaire terminated; otherwise, for the following items, the respondents were asked where they had acquired their knowledge of EBP and if they were confident with it. The final questions in this section assessed the respondent's actual knowledge of EBP. For instance, item 14 investigated familiarity with some terms often found in the literature, item 15 asked which study design is considered the most reliable and item 16 investigated whether the respondent understood 
the results of a meta-analysis from a given forest plot. Most of the items in section 3 were statements to which respondents had to express their agreement on a fivepoint Likert scale, with 'strongly agree' and 'strongly disagree' as anchors, about their perception and use of EBP. In section 4, item 25, the respondents had to state whether or not they felt barriers to the utilisation of EBP exist. If they stated there were no barriers to its utilisation, the questionnaire terminated as a conditional question. Otherwise, for item 26, the respondents had to express their opinion about the presence of barriers to the implementation of EBP and to rank them from the most to the least important.

\section{Statistical analyses}

Descriptive statistics are presented as medians and interquartile ranges (IQRs) or absolute values, percentages and frequencies, when appropriate. The response frequencies were represented and analysed in tabular and graphic formats using Microsoft Excel or PowerPoint 2010. An automated count of response rate was acquired for each of the four sections in order to determine whether the questionnaires were terminated earlier (ie, users did not go through all four questionnaire sections). We dichotomised the responses to the five-point items as 'disagree' versus 'agree' ('strongly disagree, disagree and neutral' versus 'agree and strongly agree' categories). Demographic characteristics (eg, sex, age and level of education) were collapsed into categories. We performed logistic regression analysis to examine the association between knowledge of components of the EBP model (questions related to whether patient values and clinical expertise are considered in the EBP model) and demographic characteristics of the respondent (age, sex, working time and level of education). Results were considered statistically significant when $\mathrm{p}<0.05$. ORs and their 95\% CIs were determined for each level of the independent variables. ORs in this context describe the likelihood of demonstrating a particular behaviour and use (eg, understanding that the EBP model comprises patient values) given a particular characteristic (eg, age). One level of each demographic characteristic was used as the reference group against which the odds of demonstrating the behaviour and use at all other levels of the variable were measured. The reference group was the last category to allow the most salient interpretation of results. CIs provided information about the precision of the estimates. We chose to examine univariate rather than multivariate associations for presenting our data at its most simple level so as to have a foundation for future hypothesis testing. Data were exported from the SurveyMonkey and analysed with STATA 15 software. ${ }^{25}$

\section{RESULTS \\ Respondent characteristics}

A total of 2000 physiotherapists constituted the number of potential survey questionnaire respondents. Based on this number, the response rate was moderate $(1289 / 2000$, $64.5 \%)$. The number of respondents was far higher than our target sample $(n=370)$. The response rate decreased from section 1 to section 3 due to the presence of conditional branching logic items (item 9 and item 25) in the survey questionnaire. The response rate for each completed section differed: $56 \%(n=1113)$ response rate for section 1 (demographics); 42\% ( $\mathrm{n}=837)$ for section 2 (knowledge of EBP) and 41\% ( $\mathrm{n}=818)$ for section 3 (use and perceived effectiveness of EBP). The sample included in each section is reported in figure 1.

\begin{tabular}{|}
2000 expected answers \\
916 answers to the first email \\
373 answers to the second email \\
1289 received answers \\
\hline
\end{tabular}

\begin{tabular}{|l|r|}
\hline \begin{tabular}{|l|l|} 
Respondents' characteristics \\
Knowledge
\end{tabular} & 1113 completed up to the demographic section \\
\hline Use and perceived effectiveness & 837 completed up to the knowledge section \\
\hline Barriers & 815 completed up to the utilization section \\
\hline
\end{tabular}

Figure 1 Flow diagram of the study. 
Table 1 Sample characteristics

\begin{tabular}{lll} 
Characteristic* & & $\begin{array}{l}\text { Frequency } \\
(\%)\end{array}$ \\
\hline Sex $(\mathrm{n}=1289)$ & Male & 48 \\
& Female & 52 \\
Age, years & $<29$ & 28 \\
$(\mathrm{n}=1289)$ & $29-38$ & 31 \\
& $39-49$ & 18 \\
& $>49$ & 23 \\
Workplace† & Private office & 59 \\
(n=1113) & Teaching hospital & 7 \\
& Hospital & 20 \\
& Nursing home & 15 \\
& Unemployed & 2 \\
& Other & 17 \\
Working time & Clinical practice & 87 \\
spent in: & Research & 11 \\
(average) & Teaching & 6 \\
(n=1113) & Management/leadership & 2 \\
\hline
\end{tabular}

${ }^{*}$ The absolute number of respondents varies for each variable due to missing data.

†Percentage may exceed $100 \%$ because some items allowed more than one answer.

The median age of the respondents was 35 years (IQR $28-47$ ), and $52 \%$ were women. Around $60 \%$ of respondents worked in a private practice $(653 / 1113)$ and $27 \%$ in a hospital (305/1113); 87\% spent most of their work time in clinical practice $(968 / 1113)$. Table 1 presents the demographic characteristics of the sample.

\section{EBP knowledge and ability to critically appraise literature}

Two respondents skipped this section. A total of 1111 respondents answered the item investigating knowledge of EBP principles. The majority $(85 \%)$ stated that they knew the EBP model. The most frequent channels for learning the principles of EBP were conferences/meetings $(48 \%)$, distance and residential learning courses $(35 \%)$, and advanced continuing professional educational courses $(35 \%)$. Only $23 \%$ of respondents stated they learnt about EBP during their undergraduate studies (online supplementary file 2).

Regarding the sources physiotherapists consult to solve clinical problems, the majority of respondents stated that their preferred information channels were discussion with peers $(80 \%)$ and literature search (86\%); $30 \%$ stated that they relied on their own experience. In addition, $78 \%$ stated they felt competent about applying EBP, whereas $1.2 \%$ stated they felt completely unable to apply EBP. More than half (61\%) were confident in their ability to critically appraise quality assessments of study design and statistical analysis. Many stated they understood the meaning of the terms 'RCTs' (72\%), 'statistical significance' (65\%) and 'meta-analysis' (52\%), but few could explain the terms 'forest plot' $(17 \%)$ and 'confidence intervals' (38\%) (table 2). In addition, while $82 \%$ correctly identified the best study design to evaluate an intervention, only $20 \%$ were able to identify the result from the overall estimate of a given meta-analysis.

\section{Use and perceived effectiveness of EBP}

An overwhelming $90 \%$ of respondents agreed that EBP is useful, comprehensive of patient values and effective, which demonstrated an overall positive attitude towards its use $(90 \%)$. But while $90 \%$ knew that the scientific literature makes up part of the EBP, many respondents failed to consider the role of patients' desire $(56 \%)$ and clinical expertise $(39 \%)$ as part of the EBP process (figure 2).

In a typical month, $59 \%$ of the respondents stated they read between one and five articles and only $9 \%$ said they did not. In addition, 55\% stated that they make clinical decisions based on their scientific readings, $80 \%$ expressed a need to increase their use of EBP and 69\% reported that it would benefit their career.

\section{Association between sample characteristics and EBP knowledge}

We found a statistically significant association between items related to how physiotherapists perceived EBP principles (patient values and clinical expertise) and sample demographic variables entered into the model (age, sex, working time, level of education) (table 3). With regard to the questionnaire item on patients' values as part of the EBP model, young physiotherapists (age $<29$ years)

Table 2 Perceived knowledge of terms (837 responded, 453 skipped)

\begin{tabular}{lllcr}
\hline & $\begin{array}{l}\text { Understood and could explain } \\
\text { No (\%) }\end{array}$ & $\begin{array}{l}\text { Understood somewhat } \\
\text { No (\%) }\end{array}$ & $\begin{array}{l}\text { Did not understand } \\
\text { No (\%) }\end{array}$ & $\begin{array}{l}\text { Unknown } \\
\text { No (\%) }\end{array}$ \\
\hline Randomised controlled trials & $604(72)$ & $192(23)$ & $41(5)$ & $0(0)$ \\
\hline Meta-analysis & $439(52)$ & $304(37)$ & $86(10)$ & $8(1)$ \\
Relative risk & $250(30)$ & $428(51)$ & $135(16)$ & $24(3)$ \\
Statistical significance & $543(65)$ & $246(29)$ & $41(5)$ & $7(1)$ \\
Forest plot & $144(17)$ & $197(24)$ & $147(17)$ & $349(42)$ \\
\hline Intention to treat & $255(30)$ & $223(27)$ & $167(20)$ & $192(23)$ \\
Confidence interval & $316(39)$ & $271(32)$ & $176(18)$ & $104(11)$ \\
\hline
\end{tabular}


In your opinion, the preferences of patients are included in the EBM model?(item 18)
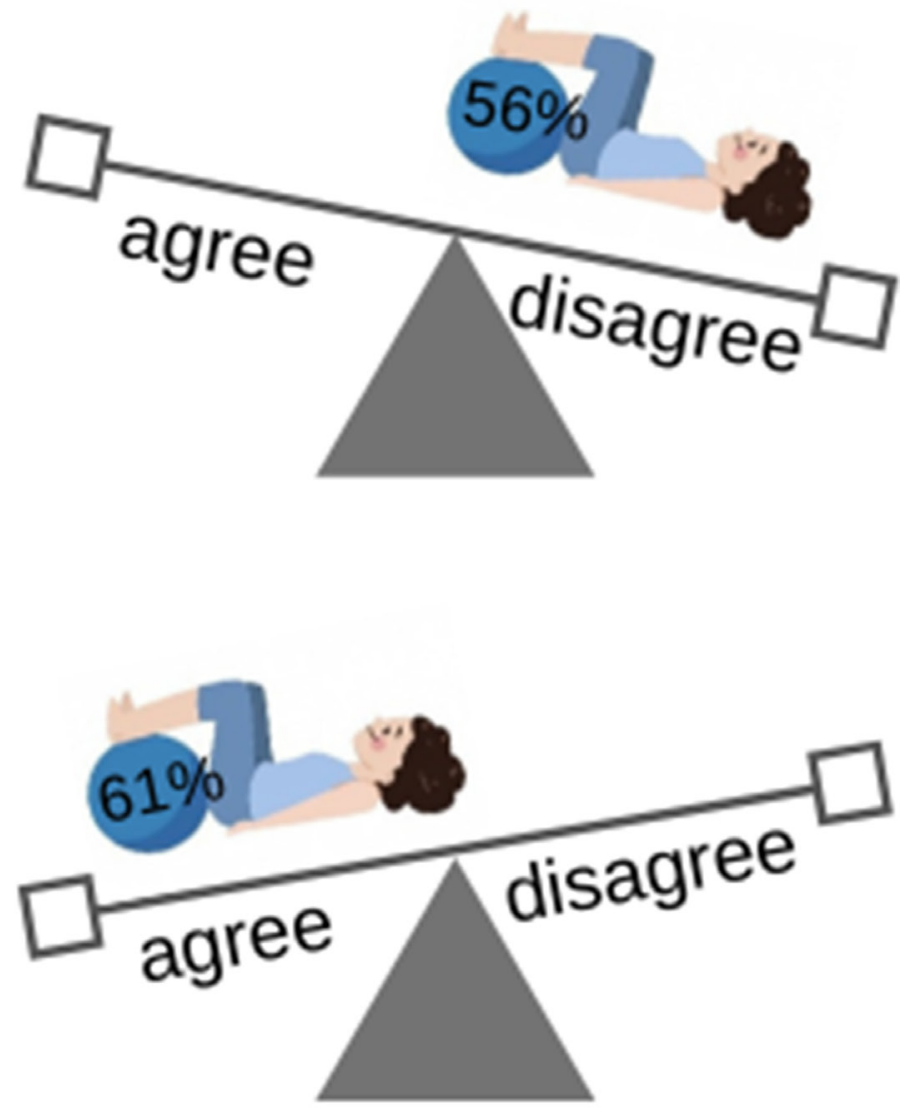

\author{
In your opinion, the \\ scientific literature is \\ useful in your clinical \\ practice? (item 20)
}

Figure 2 Perceived knowledge of the basic principles of Evidence-based Practice: patients' values, clinical expertise and scientific literature. EBM, Evidence-based Medicine.

seemed to be more aware of patient's value in the EBP model than their older counterparts (age $>49$ years) $(\mathrm{OR}$ $1.57,95 \%$ CI 1.02 to 2.42 ); being male increased the odds as well (OR $0.50,95 \%$ CI 0.38 to 0.67 ). Physiotherapists who work in patient care (eg, clinical practices) were less likely to report they understood the EBP model (OR 0.99, $95 \%$ CI 0.98 to 0.99 ) than those who work in another setting. In contrast, respondents working in research (OR $1.02,95 \% \mathrm{CI} 1.01$ to 1.03 ) and teaching (OR $1.01,95 \% \mathrm{CI}$ 1.002 to 1.02 ) were more likely to recognise patient's value as part of the EBP model, and respondents with an MSc degree (OR 2.06, 95\% CI 1.31 to 3.21) were twice more likely than those without an MSc degree to recognise it. The same difference was observed for respondents with a higher academic degree (first level Specialist Master's degree, OR 2.69, 95\% CI 1.98 to 3.64; Doctor of Philosophy, OR 10.33, 95\% CI 1.28 to 83.00).

Regarding the questionnaire item on clinical expertise as part of the EBP model, male respondents were more likely to include expertise in the EBP model (OR 0.65, $95 \%$ CI 0.49 to 0.86 ). Respondents working in patient care (OR $0.99,95 \%$ CI 0.98 to 0.99 ) seemed less likely to 
Table 3 Association between actual knowledge of EBP and selected variables

\begin{tabular}{|c|c|c|c|c|c|}
\hline & Characteristics & & & Odds ratio $(95 \% \mathrm{Cl})$ & $\begin{array}{l}\text { Model P } \\
\text { value* }^{*}\end{array}$ \\
\hline \multirow{18}{*}{$\begin{array}{l}\text { In your opinion, are } \\
\text { patients' values and } \\
\text { preferences a part of } \\
\text { the EBP model? }\end{array}$} & \multirow[t]{4}{*}{ Age (years) $†$} & \multirow[t]{4}{*}{$(n=818)$} & $<29$ & $1.57(1.02$ to 2.42$) \ddagger$ & \multirow[t]{4}{*}{0.001} \\
\hline & & & $29-38$ & $1.03(0.66$ to 1.59$)$ & \\
\hline & & & $39-49$ & 0.68 (0.39 to 1.17$)$ & \\
\hline & & & $>49$ & Reference & \\
\hline & \multirow[t]{2}{*}{ Sex§ } & \multirow[t]{2}{*}{$(n=818)$} & Female & 0.50 (0.38 to 0.67$) \ddagger$ & \multirow[t]{2}{*}{0.000} \\
\hline & & & Male & Reference & \\
\hline & \multirow[t]{4}{*}{ Working time } & $(n=814)$ & Patient care & $0.99(0.98$ to 0.995$) \neq$ & 0.002 \\
\hline & & $(n=567)$ & Research & $1.02(1.01$ to 1.03$) \ddagger$ & 0.001 \\
\hline & & $(n=609)$ & Teaching & $1.01(1.002$ to 1.02$) \ddagger$ & 0.015 \\
\hline & & $(n=492)$ & Management & 1.00 (0.98 to 1.02$)$ & 0.62 \\
\hline & \multirow[t]{8}{*}{ Level of education } & \multirow[t]{8}{*}{$(n=818)$} & Bachelor's degree & $1.04(0.75$ to 1.45$)$ & 0.81 \\
\hline & & & Master of Science degree & 2.06 (1.31 to 3.21$) \ddagger$ & 0.001 \\
\hline & & & First level Specialist Master's degree & $2.69(1.98$ to 3.64$) \ddagger$ & 0.000 \\
\hline & & & $\begin{array}{l}\text { Second level Specialist Master's } \\
\text { degree }\end{array}$ & 0.84 (0.14 to 5.07$)$ & 0.85 \\
\hline & & & $\begin{array}{l}\text { Advanced continuing professional } \\
\text { education }\end{array}$ & $1.06(0.80$ to 1.42$)$ & 0.67 \\
\hline & & & Doctor of Philosophy (PhD) & $10.33(1.28$ to 83.00$) \ddagger$ & 0.005 \\
\hline & & & $\begin{array}{l}\text { Distance and residential learning } \\
\text { course }\end{array}$ & $1.00(0.75$ to 1.34$)$ & 0.99 \\
\hline & & & Conferences/meetings & $1.40(1.06$ to 1.85$) \neq$ & 0.015 \\
\hline \multirow{18}{*}{$\begin{array}{l}\text { In your opinion, is } \\
\text { clinical expertise a part } \\
\text { of the EBP model? }\end{array}$} & \multirow[t]{4}{*}{ Age (years)† } & \multirow[t]{4}{*}{$(n=818)$} & $<29$ & 1.43 (0.93 to 2.21$)$ & \multirow[t]{4}{*}{0.11} \\
\hline & & & $29-38$ & $1.00(0.65$ to 1.55$)$ & \\
\hline & & & $39-49$ & 0.97 (0.57 to 1.64$)$ & \\
\hline & & & $>49$ & Reference & \\
\hline & \multirow[t]{2}{*}{ Sex§ } & \multirow[t]{2}{*}{$(n=818)$} & Female & $0.65(0.49$ to 0.86$) \ddagger$ & \multirow[t]{2}{*}{0.008} \\
\hline & & & Male & Reference & \\
\hline & \multirow[t]{4}{*}{ Working time $\emptyset$} & $(n=814)$ & Patient care & $0.99(0.98$ to 0.99$) \ddagger$ & 0.032 \\
\hline & & $(n=567)$ & Research & 1.01 (0.99 to 1.02$)$ & 0.24 \\
\hline & & $(n=609)$ & Teaching & 1.01 (0.99 to 1.02$)$ & 0.14 \\
\hline & & $(n=492)$ & Management & $0.98(0.97$ to 1.01$)$ & 0.32 \\
\hline & \multirow[t]{8}{*}{ Level of education } & \multirow[t]{8}{*}{$(n=818)$} & Bachelor's degree & 1.25 (0.89 to 1.76$)$ & 0.19 \\
\hline & & & Master of Science degree & $2.16(1.31$ to 3.58$) \ddagger$ & 0.002 \\
\hline & & & $\begin{array}{l}\text { First level Specialist Master's degree } \\
\text { (Postgraduate) }\end{array}$ & $1.99(1.45$ to 2.75$) \ddagger$ & 0.000 \\
\hline & & & $\begin{array}{l}\text { Second level Specialist Master's } \\
\text { degree (Postgraduate) }\end{array}$ & 0.97 (0.16 to 5.86$)$ & 0.98 \\
\hline & & & $\begin{array}{l}\text { Advanced continuing professional } \\
\text { education }\end{array}$ & $0.90(0.67$ to 1.21$)$ & 0.49 \\
\hline & & & Doctor of Philosophy (PhD) & $0.26(0.65$ to 42.27$)$ & 0.06 \\
\hline & & & $\begin{array}{l}\text { Distance and residential learning } \\
\text { course }\end{array}$ & $1.08(0.80$ to 1.45$)$ & 0.61 \\
\hline & & & Conferences/meetings & $1.20(0.91$ to 1.59$)$ & 0.20 \\
\hline
\end{tabular}

First level Master's degree: equivalent to postgraduate diploma: programme for which a Bachelor's degree is a prerequisite.

Second level Master degree: postgraduate level for which a Master of Science degree is a prerequisite.

Advanced continuing professional education: postgraduate certification.

References categories are reported in legend.

${ }^{\star} \chi^{2}$ test.

tOR calculated using the variable $>49$ years as reference.

†Statistically significant $(\mathrm{p}<0.05)$.

§OR calculated using the variable male as reference.

IOR calculated as the ratio between the odds in the presence of characteristic variable against the odds in the absence of the variable (ie, characteristic: working time;

variable: patient care. The OR is the ratio between the odds of working in patient care against the odds of not working in patient care).

EBP, evidence-based practice. 
Table 4 Barriers to applying EBP in order of importance (\%)

\begin{tabular}{|c|c|c|c|c|c|c|c|c|c|c|}
\hline \multirow[b]{2}{*}{ Type of barrier } & \multicolumn{10}{|c|}{ Order of importance from the most to the least (\%) } \\
\hline & 1st & 2nd & 3nd & 4th & 5th & 6th & 7th & 8th & 9th & 10th \\
\hline Lack of interest & 10.7 & 8.3 & 5.6 & 6.9 & 6.2 & 7.0 & 10.2 & 10.7 & 10.7 & 23.7 \\
\hline Lack of time & 23.0 & 13.2 & 15.1 & 10.0 & 9.0 & 9.0 & 5.8 & 5.5 & 5.8 & 3.7 \\
\hline $\begin{array}{l}\text { Difficulty in critically appraising } \\
\text { literature and statistical analysis }\end{array}$ & 9.7 & 17.8 & 16.5 & 16.7 & 16.9 & 9.3 & 6.0 & 4.0 & 2.1 & 1.1 \\
\hline $\begin{array}{l}\text { Difficulty applying literature } \\
\text { findings to individual patients }\end{array}$ & 9.5 & 11.4 & 12.7 & 14.1 & 12.7 & 16.9 & 11.3 & 5.6 & 5.5 & 0.5 \\
\hline $\begin{array}{l}\text { Lack of financial and } \\
\text { organisational support (computer, } \\
\text { access to databases) }\end{array}$ & 8.4 & 7.4 & 8.6 & 8.8 & 8.8 & 10.5 & 20.6 & 12.8 & 7.4 & 6.7 \\
\hline $\begin{array}{l}\text { Language of scientific } \\
\text { publications }\end{array}$ & 4.8 & 3.0 & 5.1 & 6.3 & 7.4 & 8.6 & 10.0 & 15.6 & 30.8 & 8.4 \\
\hline $\begin{array}{l}\text { Unfamiliarity with using the } \\
\text { computer/technology }\end{array}$ & 1.4 & 3.2 & 2.6 & 3.9 & 2.1 & 4.8 & 6.2 & 11.6 & 22.3 & 42.0 \\
\hline
\end{tabular}

EBP, Evidence-based Practice.

understand the EBP model than respondents not working with patients (OR $0.65,95 \%$ CI 0.49 to 0.86 ). Finally, having a higher academic degree (MSc, OR 2.16, 95\% CI 1.31 to 3.58; first level Specialist MSc, OR 1.99, 95\% CI 1.45 to 2.75 ) was associated with twice the likelihood of including clinical expertise in the EBP model (table 3).

\section{Perceived barriers to using EBP in clinical practice}

Respondents stated that major barriers to applying EBP exist $(570 / 815,75 \%)$ : lack of time and lack of ability to critically appraise the literature were rated as the top two barriers. Lack of time was ranked as the most important (table 4).

\section{DISCUSSION}

\section{Main findings}

The questionnaire response rate of $64.5 \%$ (1289 physiotherapists out of 2000 invited) was higher than the required sample size of 370 , and so can be considered representative of physiotherapists belonging to the AIFI. Overall, the respondents stated that they held a positive attitude towards EBP and that their knowledge about it was extensive. The majority overrated their knowledge, however, and demonstrated a shallow awareness of EBP compared with the original model described by Sackett et $a l^{26}$ The gap between perceived and actual knowledge of EBP is relevant and can result in inadequate practice, potentially increasing the risk 'to over-egg the pudding', which indicates the need to achieve the right balance in healthcare. $^{27}$
Our survey findings are similar to those obtained from American physiotherapists 15 years ago $^{12}$ and, more recently, from Ghanaian physiotherapists who demonstrated an inadequate knowledge of EBP. ${ }^{14}$ In contrast, Brazilian physiotherapists showed that they were better acquainted with EBP since they included patient preferences as part of the decision-making process. ${ }^{15}$ In Europe, Swedish physiotherapists consider patient preferences when treating according to guidelines and so adhere to the EBP process. ${ }^{28}$ However, the international context in which physiotherapists deliver healthcare might differ from the scenario in Italy, where direct access is not yet completely implemented and fewer years of study than in other countries are required for qualifying as a physiotherapist. $^{2930}$

In our sample, younger respondents were noted to be more familiar with EBP than their older, more experienced colleagues. Our findings are shared by similar observations that the level of EBP knowledge is influenced by the time since school graduation. In general, recent graduates are more likely to follow EBP than physiotherapists with more clinical experience. ${ }^{11}$ We also observed that EBP knowledge differed depending on the respondent's level of education and workplace setting. ${ }^{11-13}$ Indeed, personal and organisational characteristics can significantly influence attitudes, beliefs, use of EBP and perceived support. $^{31}$

Of the total of respondents with a Bachelor's degree, only one-fifth had received education in EBP. The levels of education most closely associated with greater EBP knowledge are the graduate and postgraduate levels. The 
teaching of EBP principles in undergraduate courses remains scarce, although it is widely considered essential for improving the quality of healthcare and patient outcomes. In many countries, studies have highlighted that physiotherapists require more training in EBP in order to acquire confidence in using it ${ }^{11}$ however, the teaching of EBP-oriented skills in undergraduate physiotherapy programmes began only two decades ago. ${ }^{32-34}$ Since then, EBP has been increasingly integrated into the core curriculum of undergraduate and postgraduate healthcare programmes and continuing professional education. ${ }^{35-37}$ Italy is no exception: the teaching of EBP became an integral part of the core curriculum of physiotherapy in 2005. ${ }^{22}$ This statement is consistent with our study's finding that younger Italian physiotherapists (age $<29$ years) are more likely to hold positive attitudes towards EBP, which indicates that EBP will be more widely adopted by future generations of physiotherapists.

Moreover, better informed knowledge, use and attitudes towards EBP may be most strongly associated with completion of a Master's degree programme, whereas short, continuing professional educational courses have limited effectiveness. Accordingly, it might be appropriate to support access to Master's degree courses at the national level and to improve the quality of short training courses and structure them on EBP principles.

The perceived and actual knowledge and the use of evidence from the scientific literature differed among respondents. While the majority felt able to conduct a literature search and to critically appraise the statistical analysis in a scientific article, few demonstrated that they understood the results of a meta-analysis from a given forest plot. Nevertheless, the respondents appeared to have great confidence in the authority of published scientific literature and stated that their clinical decisions rarely relied on their experience alone: the attitude and the attempt to introduce findings from the scientific literature in the clinical context is congruent with their positive attitude towards EBP.

The discrepancy between actual knowledge and practice of EBP could be a consequence of the myriad information sources accessible in scientific databases and non-scientific channels, such as Doctor Google or social networks. Healthcare professionals, including physiotherapists, need to develop their analytical skills to confront this overabundance of information in their professional life: exercise a careful selection of what to read and what not to for both quality and quantity. ${ }^{38}$ Indeed, threequarters of our respondents perceived barriers that limit their ability to critically appraise the literature. ${ }^{11-13283940}$

\section{Strengths and limitations}

This is the first study to examine perceived and actual knowledge of EBP among physiotherapists in Italy. Although the response rate was high-moderate $(64.5 \%)$, the study has several limitations that need to be considered when analysing the results. First, our sample included only AIFI members who may not be representative of the entire population of Italian physiotherapists, as it might be that AIFI members are more likely to participate in a survey about their profession. Moreover, respondents, as AIFI members, were perhaps more open towards EBP but overestimated their knowledge: the self-reported nature of the data might have influenced the gap between perceived and actual knowledge. This gap constituted a small part of the broader scope of the study, the aim of which is to test our preliminary hypothesis about the gap and to provide a concise snapshot view that can be better assessed by validated instruments, such as the Fresno Test or the Berlin Questionnaire, in a future study. ${ }^{41}{ }^{42}$ Nonetheless, before the national regulatory bord (Federazione nazionale Ordini dei Tecnici Sanitari di Radiologia Medica e delle Professioni Sanitarie Tecniche, della Riabilitazione e della Prevenzione - TSRM-PSTRP) of Italian physiotherapists was established in 2018, the AIFI was the only professional society for physiotherapists in Italy and was not constituted as a scientific society. Second, sending out only one reminder to participate in the survey might have limited the number of potential respondents. A potential non-response bias might have affected the results and interpretation of this cross-sectional study. Factors such as questionnaire length, the term 'survey' in the text of the e-mail, and the non-inclusion of incentives might have influenced the rate response: a Cochrane review showed a lower odds of response in such situations. ${ }^{43}$

That said, the final percentage of respondents did not seem to bias our results, as we reached the planned sample target down to the final survey questionnaire items. Third, we dichotomised the dependent variables, conflating all responses into positive/negative categories. This might have resulted in a loss of some information, though we replicated what previous studies of the same design have done ${ }^{12}$ in order to report useful findings. Finally, the accuracy of data on perceived knowledge is uncertain as the data were collected via a self-reported survey.

\section{Implication for research, practice and education}

We believe that research can help to increase the dissemination of knowledge about and the adoption of EBP among physiotherapists. A focus for future research should be to concentrate efforts in conducting high-quality research and teaching master classes devoted to EBP topics $^{44}$ and promoting research learning programmes as knowledge translation interventions to improve the use of EBP and clinical practice guidelines (CPGs) in physiotherapy. ${ }^{45}$ CPGs, defined as 'systematically developed statements to assist practitioner and patient decisions about appropriate healthcare for specific clinical circumstances' (definition adopted by the European Region of the World Confederation for Physiotherapy), can be used to bridge the research to practice gap and promote EBP and present research findings to clinicians in a synthetic format without missing any elements of the EBP model. ${ }^{9}$

CPGs based on the Grades of Recommendation, Assessment, Development, and Evaluation (GRADE) approach 
are conducted in a standardised and transparent manner: GRADE rates the quality of evidence and provides the strength of recommendations by considering the 'estimates of effect for desirable and undesirable outcomes of interest', the 'confidence in the estimates of effect', the 'estimates of values and preferences' and the 'resource use'. ${ }^{46}$ This approach helps readers interpret a CPG and enhances CPG adherence by health professionals. In some countries, professional liability is legally regulated and great importance placed on adherence to CPGs in clinical practice; compliance with CPGs is an element in attributing professional responsibility in adverse events. Furthermore, to improve physiotherapist adherence to CPGs, computerised decision support systems could provide actionable recommendations or management options that are intelligently filtered or presented at appropriate times to improve efficiency in healthcare. ${ }^{47}$

For these reasons, both national and international initiatives are warranted for the implementation of CPGs in physiotherapy. The production of CPGs, or at least a synthesis of the evidence underpinning them, could be (and is to some extent) coordinated on a national level, while implementation may be more suitable for local adaptation. ${ }^{48}$ For instance, the recently created Italian National Guidelines System ${ }^{49}$ includes a list of scientific societies that can contribute to drafting CPGs (including the AIFI), a process based on the GRADE method for the production, adaptation and updating of CPG. By searching this database, healthcare professionals can find continuously updated CPGs and good quality practices.

We appeal for a critical use and appraisal of EBP. EBP should be included in the professional education of physiotherapists and introduced at the undergraduate curriculum. Investing in the training of physiotherapists is essential for growing the skills of critical appraisal of Evidence-based Physiotherapy and a key means to reduce the waste created by obsolete, futile or harmful interventions. ${ }^{8}$ For instance, initiatives such as INQUIRE (INcreasing QUality In patient-oriented academic clinical Research) have designed a roadmap that provides guidance for academics and researchers in developing quality enhancement initiatives. ${ }^{50}$ The PEAK (The Physical therapist-driven Education for Actionable Knowledge translation) educational programme was designed to promote the integration of research evidence from physiotherapy into clinical decision making. ${ }^{19} 5152$ Finally, engaging in research can contribute to being an attractive employer and boost the application of EBP. ${ }^{13}$ Promoting professional education is key to minimise 'the mismatch between what clinical researchers do and what patients need' ${ }^{53}$

\footnotetext{
Author affiliations

${ }^{1}$ Unit of Clinical Epidemiology, IRCCS Istituto Ortopedico Galeazzi, Milano, Italy ${ }^{2}$ Department of Rehabilitation and Functional Recovery, IRCCS San Raffaele Scientific Institute, Milan, Italy

${ }^{3}$ Physiotherapy Degree Course, Vita-Salute San Raffaele University, Milan, Italy

${ }^{4}$ Azienda Provinciale per i Servizi Sanitari (APSS), Trento, Italy

${ }^{5}$ Physiotherapy Degree Course, University of Verona, Verona, Italy
}

Acknowledgements The authors thank Leonardo Piano for providing support through the AIFI, Riccardo Negri for assisting in data collection, the physiotherapists who participated in the survey.

Contributors SG and GC were primarily responsible for study conception and design and for data analysis and interpretation. All authors (SG, GC, DC, SC) had full access to all of the data in the study and take responsibility for the integrity of the data and the accuracy of the data analysis. DC led the writing of the first draft of the manuscript. All authors (SG, GC, DC, SC) contributed to drafting and revising the manuscript. SG is the guarantor. All authors (SG, GC, DC, SC) read and approved the final manuscript.

Funding The study was supported by the Italian Ministry of Health, Linea 3 (Consapevolezza e competenza dei principi dell'Evidence-based Medicine (EBM) in coorti di professionisti sanitari coinvolti nell'ambito dei disordini muscoloscheletrici).

Competing interests None declared.

Patient and public involvement Patients and/or the public were not involved in the design, or conduct, or reporting, or dissemination plans of this research.

Patient consent for publication Obtained. Written informed consent was assumed if the respondents completed and submitted the survey after reading the purpose statement of the study.

Ethics approval We conducted this study in compliance with the principles outlined in the Declaration of Helsinki. The survey questionnaire was filled out anonymously, and responses could not be traced back to respondents. Written informed consent was assumed if the respondents completed and submitted the survey after reading the purpose statement of the study. Ethics approval was not required.

Provenance and peer review Not commissioned; externally peer reviewed.

Data availability statement Data are available in a public, open access repository. Availability of data and material: All data generated or analysed during this study are available at https://osf.io/8xb6p/?view_only=1c6fd76403c04a82942799b9 dee952c8.

Open access This is an open access article distributed in accordance with the Creative Commons Attribution Non Commercial (CC BY-NC 4.0) license, which permits others to distribute, remix, adapt, build upon this work non-commercially, and license their derivative works on different terms, provided the original work is properly cited, appropriate credit is given, any changes made indicated, and the use is non-commercial. See: http://creativecommons.org/licenses/by-nc/4.0/.

\section{ORCID iDs}

Greta Castellini http://orcid.org/0000-0002-3345-8187

Davide Corbetta http://orcid.org/0000-0003-3981-7248

Silvia Gianola http://orcid.org/0000-0003-3770-0011

\section{REFERENCES}

1 Sackett DL, Rosenberg WM, Gray JA, et al. Evidence based medicine: what it is and what it isn't. BMJ 1996;312:71-2.

2 Haynes RB, Devereaux PJ, Guyatt GH. Physicians' and patients' choices in evidence based practice. BMJ 2002;324:1350.

3 Sackett DL. Evidence-based medicine. Spine 1998;23:1085-6.

4 Condon C, McGrane N, Mockler D, et al. Ability of physiotherapists to undertake evidence-based practice steps: a scoping review. Physiotherapy 2016;102:10-19.

5 Scurlock-Evans L, Upton P, Upton D. Evidence-based practice in physiotherapy: a systematic review of barriers, enablers and interventions. Physiotherapy 2014;100:208-19.

6 Costa LOP, Maher CG, Lopes AD, et al. Transparent reporting of studies relevant to physical therapy practice. Rev Bras Fisioter 2011;15:267-71.

7 Maher CG, Moseley AM, Sherrington C, et al. A description of the trials, reviews, and practice guidelines indexed in the PEDro database. Phys Ther 2008;88:1068-77.

8 Jesus TS GS, Castellini G, Colquhoun $\mathrm{H}$, et al. Evolving trends in physiotherapy research publications between 1995 and 2015. Physiother Can 2019.

9 Grol R, Grimshaw J. Evidence-based implementation of evidencebased medicine. Jt Comm J Qual Improv 1999;25:503-13.

10 Barnard S, Wiles R. Evidence-based physiotherapy: physiotherapists' attitudes and experiences in the Wessex area. Physiotherapy 2001;87:115-24. 
11 Iles R, Davidson M. Evidence based practice: a survey of physiotherapists' current practice. Physiother Res Int 2006;11:93-103.

12 Jette DU, Bacon K, Batty C, et al. Evidence-based practice: beliefs, attitudes, knowledge, and behaviors of physical therapists. Phys Ther 2003;83:786-805.

13 Nilsagård Y, Lohse G. Evidence-based physiotherapy: a survey of knowledge, behaviour, attitudes and prerequisites. Adv Physiother 2010;12:179-86.

14 Quartey J, Kwakye S. Barriers to evidence-based physiotherapy practice for stroke survivors in Ghana. S Afr J Physiother 2018;74:423.

15 Silva TM, Costa LCM, Costa LOP. Evidence-based practice: a survey regarding behavior, knowledge, skills, resources, opinions and perceived barriers of Brazilian physical therapists from São Paulo state. Braz J Phys Ther 2015;19:294-303.

16 Ramírez-Vélez R, Correa-Bautista JE, Muñoz-Rodríguez DI, et al. Evidence-based practice: beliefs, attitudes, knowledge, and skills among Colombian physical therapists. Colomb Med 2015;46:33-40.

17 Alshehri MA, Alalawi A, Alhasan H, et al. Physiotherapists' behaviour, attitudes, awareness, knowledge and barriers in relation to evidencebased practice implementation in Saudi Arabia: a cross-sectional study. Int J Evid Based Healthc 2017;15:127-41.

18 Arnadottir SA, Gudjonsdottir B. Icelandic physical therapists' attitudes toward adoption of new knowledge and evidencebased practice: cross-sectional web-based survey. Phys Ther 2016;96:1724-33.

19 Tilson JK, Mickan S, Sum JC, et al. Promoting physical therapists' use of research evidence to inform clinical practice: part 2--a mixed methods evaluation of the PEAK program. BMC Med Educ 2014;14:126.

20 Bennett C, Khangura S, Brehaut JC, et al. Reporting guidelines for survey research: an analysis of published guidance and reporting practices. PLoS Med 2010;8:e1001069.

21 Eysenbach $\mathrm{G}$. Improving the quality of web surveys: the checklist for reporting results of Internet E-Surveys (cherries). J Med Internet Res 2004;6:e34.

22 Bertozzi LBS, Costi S, Pillastrini P. Il core curriculum del fisioterapista, 2005.

23 James Bartlett E E, Kotrlik JW, Higgins CC. Organizational research: determining appropriate sample size in survey research. ITLPJ 2001;19.

24 Robert Herbert GJ, Hagen KB, Mead J, et al. Practical evidencebased physiotherapy, 2012

25 StataCorp. Stata Statistical Software: Release 15. College Station, TX: StataCorp LLC, 2017.

26 Sackett D, Richardson W, Rosenberg W, et al. Evidence-Based medicine: how to practice and teach EBM. 1 edn. London: Churchill Livingstone, 1997.

27 Maher CG, O'Keeffe M, Buchbinder R, et al. Musculoskeletal healthcare: have we over-egged the pudding? Int J Rheum Dis 2019;22:1957-60.

28 Heiwe S, Kajermo KN, Tyni-Lenné R, et al. Evidence-based practice: attitudes, knowledge and behaviour among allied health care professionals. Int J Qual Health Care 2011;23:198-209.

29 World Confederation for Physical Therapy. Entry level physical therapy education programmes. Available: https://www.wcpt.org/ education/Entry-level-physical-therapy-education-programmes

30 American Physical Therapy Association. Physical therapist (PT) education overview, 2019. Available: https://www.apta.org/ PTEducation/Overview/

31 Nascimento LR, Fernandes MOP, Teixeira-Salmela LF, et al. Personal and organizational characteristics associated with evidence-based practice reported by Brazilian physical therapists providing service to people with stroke: a cross-sectional mail survey. Braz J Phys Ther 2019. doi:10.1016/j.bjpt.2019.05.003. [Epub ahead of print: 28 May 2019].

32 Aronoff N, Stellrecht E, Lyons AG, et al. Teaching evidencebased practice principles to prepare health professions students for an interprofessional learning experience. J Med Libr Assoc 2017;105:376-84.

33 Perraton L, Machotka Z, Grimmer K, et al. Embedding evidencebased practice education into a post-graduate physiotherapy program: eight years of pre-post course evaluations. Physiother Res Int 2017;22:e1659.

34 Thomas A, Han L, Osler BP, et al. Students' attitudes and perceptions of teaching and assessment of evidence-based practice in an occupational therapy professional master's curriculum: a mixed methods study. BMC Med Educ 2017;17:64.

35 Frenk J, Chen L, Bhutta ZA, et al. Health professionals for a new century: transforming education to strengthen health systems in an interdependent world. Lancet 2010;376:1923-58.

36 Albarqouni L, Hoffmann T, Straus S, et al. Core competencies in evidence-based practice for health professionals: consensus statement based on a systematic review and Delphi survey. JAMA Netw Open 2018;1:e180281.

37 Greiner AC, Knebel E, Institute of Medicine (US) Committee on the Health Professions Education Summit;. Chapter 3, The Core Competencies Needed for Health Care Professionals. In: Health professions education: a bridge to quality. Washington (DC: National Academies Press (US), 2003. https://www.ncbi.nlm.nih.gov/books/ NBK221519/

38 Masic I, Miokovic M, Muhamedagic B. Evidence based medicine new approaches and challenges. Acta Inform Med 2008;16:219.

39 Salbach NM, Jaglal SB, Korner-Bitensky N, et al. Practitioner and organizational barriers to evidence-based practice of physical therapists for people with stroke. Phys Ther 2007;87:1284-303.

40 Minozzi S, Ruggiero F, Capobussi M, et al. [EBM, guidelines, protocols: knowledge, attitudes and utilization in the era of law on professional responsibility and safety of health care.]. Recenti Prog Med 2018;109:294-306.

41 Zwolsman SE, Wieringa-de Waard M, Hooft L, et al. Measuring evidence-based medicine knowledge and skills. The Dutch Berlin questionnaire: translation and validation. J Clin Epidemiol 2011;64:928-30.

42 Ramos KD, Schafer S, Tracz SM. Validation of the Fresno test of competence in evidence based medicine. BMJ 2003;326:319-21.

43 Edwards PJ, Roberts I, Clarke MJ, et al. Methods to increase response to postal and electronic questionnaires. Cochrane Database Syst Rev 2009;3:MR000008.

44 Hespanhol L, Vallio CS, Costa LM, et al. Understanding and interpreting confidence and credible intervals around effect estimates. Braz J Phys Ther 2019;23:290-301.

45 Stander J, Grimmer K, Brink Y. Training programmes to improve evidence uptake and utilisation by physiotherapists: a systematic scoping review. BMC Med Educ 2018;18:14.

46 Andrews JC, Schünemann HJ, Oxman AD, et al. Grade guidelines: 15. going from evidence to recommendation-determinants of a recommendation's direction and strength. J Clin Epidemiol 2013;66:726-35.

47 Moja L, Passardi A, Capobussi M, et al. Implementing an evidencebased computerized decision support system linked to electronic health records to improve care for cancer patients: the ONCOCODES study protocol for a randomized controlled trial. Implement Sci 2016;11:153.

48 Bernhardsson S, Larsson MEH, Johansson K, et al. "In the physio we trust": a qualitative study on patients' preferences for physiotherapy. Physiother Theory Pract 2017;33:535-49.

49 Mašić I. Porodična/ Obiteljska medicina principi I praksa. Avicena Sarajevo, 2007: 115-23.

50 von Niederhäusern B, Guyatt GH, Briel M, et al. Academic response to improving value and reducing waste: a comprehensive framework for increasing quality in patient-oriented academic clinical research (INQUIRE). PLoS Med 2018;15:e1002580.

51 Tilson JK, Mickan S, Howard R, et al. Promoting physical therapists' use of research evidence to inform clinical practice: part 3--long term feasibility assessment of the PEAK program. BMC Med Educ 2016;16:144.

52 Tilson JK, Mickan S. Promoting physical therapists' of research evidence to inform clinical practice: part 1--theoretical foundation, evidence, and description of the PEAK program. BMC Med Educ $2014 ; 14: 125$.

53 Liberati A. Need to realign patient-oriented and commercial and academic research. Lancet 2011;378:1777-8. 